Journal of Machine Engineering, 2020, Vol. 20, No. 1, 98-106

ISSN 1895-7595 (Print) ISSN 2391-8071 (Online)

Received: 04 November 2019 / Accepted: 28 November 2019 / Published online: 05 March 2020

CFRP, thrust force, simultaneous cutting, delamination

Kenji SHIMANA $^{1}$, Ryota KAWANO ${ }^{2 *}$, Masakazu HARADA ${ }^{1}$, Shinichi YOSHIMITSU ${ }^{1}$, Yuya KOBARU ${ }^{1}$, Eiji KONDO ${ }^{3}$

\title{
SURFACE INTEGRITY OF MACHINED SURFACE IN SIMULTANEOUS CUTTING OF CFRP
}

\begin{abstract}
Carbon fiber-reinforced plastic (CFRP), a carbon fiber composite material, has high specific strength and stiffness, and has attracted attention as a structural material for transport machines from the viewpoint of improving fuel efficiency through weight reduction. However, the exiting CFRP processing methods have several disadvantages such as high cost, tool wear due to formation of hard chips during cutting, and occurrence of delamination that degrades machining accuracy. These limitations impede the practical application of CFRP. The purpose of this study is to propose a low cost and high precision drilling method "simultaneous cutting" by stacking the different materials with CFRP. Until now, high precision hole drilling has been studied by stacking titanium on CFRP. Because CFRP and titanium parts are joined by bolts in aircraft and so on. However, in this study, an inexpensive and easy to obtain acrylic resin plate was selected as a stacking material to focus on CFRP hole drilling. On the other hand, acrylic resin plate was used for CFRP hole drilling as a waste material. As a result, it was found that the thrust force was reduced by drilling the hole with stacking CFRP between two acrylic resin plates. Furthermore, the occurrence of delamination was suppressed at both the entry and exit sides of the hole.
\end{abstract}

\section{INTRODUCTION}

Many studies have been conducted on general metal drilling until now, and methods for drilling relatively shallow holes are almost established. In recent years, research has been conducted on monitoring technology for machining deep holes with high precision $[1,2]$. Furthermore, many researchers have been studying on the drilling of difficult-toprocess materials $[3,4]$.

Carbon fiber-reinforced plastic (CFRP), has high specific strength and stiffness, and has attracted attention as a structural material for transport machines from the viewpoint of improving fuel efficiency through weight reduction. However, the exiting CFRP processing methods have several disadvantages such as high cost, tool wear due to formation

\footnotetext{
${ }^{1}$ National Institute of Technology, Kagoshima College, Japan

2 NSK Ltd.

${ }^{3}$ Kagoshima University, Kagoshima, Japan

*E-mail: shimana@kagoshima-ct.ac.jp https://doi.org/10.36897/jme/117781
} 
of hard chips during cutting, burrs, uncut fibers, and occurrence of delamination that degrades machining accuracy $[5,6]$, as shown in Fig. 1.

Furthermore, non-homogeneous structure of composites leads to various difficulties during machining such as excessive temperature and undesired surface quality [7]. These limitations impede the practical application of CFRP. To solve these problems, milling tests on CFRP plates were carried out using tools with different numbers of flute [8]. Furthermore, experiments were carried out by using eight carbide end mills with different shape and coatings obtained from different producers [9]. However, the problem is that the tools used are expensive.

On the other hand, Tanaka et al. proposed the high precision drilling by inclined planetary motion milling [10]. Sakamoto et al. proposed the high precision drilling by helical milling with cemented-carbide ball end mill [11]. However, the problem is that expensive machine tools must be used.

In practice, CFRP and titanium parts are joined by bolts in aircraft, luxury sports car and so on. Therefore, hole drilling has been studied by stacking CFRP and titanium [12, 13]. However, since titanium is also a difficult-to-cut material, special tools must be used for processing CFRP/titanium stacks.

If the use of CFRP is increased in the future, more efficient drilling will be required. On the other hand, the demand for drilling with general-purpose machine tools and inexpensive tools is also expected to increase.

The purpose of this study is to propose a high-precision drilling method by stacking highly machinable material such as acrylic resin on CFRP. For that purpose, the effect of cutting conditions on thrust force and machining accuracy was investigated by drilling CFRP/ acrylic stacks. Acrylic resin plate was used for CFRP hole drilling as a waste material. Until now, we have investigated the effect on drilling by a method "simultaneous cutting" in which acrylic resin is stacked on brass. The acrylic to be stacked was selected because it was relatively easy to obtain and easy to cut, and the chips had little effect on the machined surface of holes.

\section{EXTERIOR OF HOLE AND THRUST FORCE}

\subsection{EXPERIMENTAL PROCEDURE}

The workpiece plate was made of carbon-fiber reinforced plastic (CFRP). The top and bottom surfaces of the CFRP plate are plain woven carbon at $0^{\circ} / 90^{\circ}$. On the other hand, the interior of the CFRP plate is laminated with carbon fiber at $0^{\circ} / 90^{\circ} / 45^{\circ} /-45^{\circ}$, as shown in Fig. 1. The thickness of the CFRP plate is $6 \mathrm{~mm}$. Table 1 shows the properties of CFRP.

Figure 2 shows the experimental apparatus used for the drilling tests. The drilling tests were performed using a vertical machining centre. An acrylic resin plate was used as the material for stacking CFRP. The thickness of the acrylic resin plate was $5 \mathrm{~mm}$. The stacked workpiece was fixed with upper and lower jigs having nine holes with a diameter of $10 \mathrm{~mm}$, as shown in Fig. 2. Ten holes were drilled in the workpiece using a high-speed steel drill with a diameter of $6 \mathrm{~mm}$. Table 2 shows the cutting conditions. 


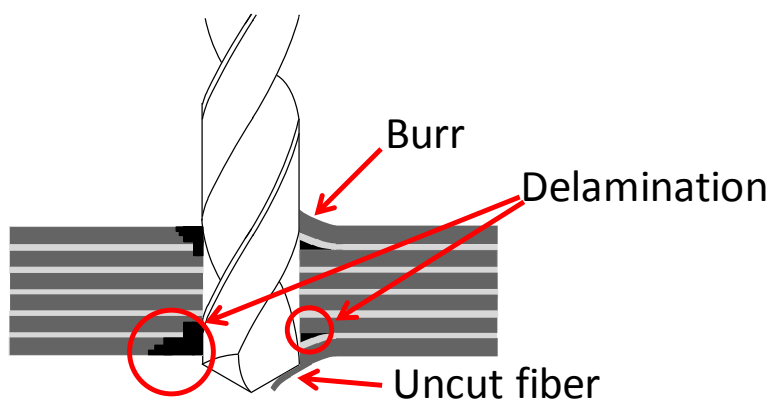

Fig. 1. Problems in drilling of CFRP

Table 1. Material properties of CFRP

\begin{tabular}{|c|c|}
\hline Carbon fiber & T700S \\
\hline Matrix & Epoxy resin \\
\hline Outer layer & Cloth $0^{\circ} / 90^{\circ}$ \\
& Single layer laminated \\
\hline Inner layer & UD $0^{\circ} / 90^{\circ} / 45^{\circ}-45^{\circ}$ \\
& Alternately laminated \\
\hline Number of layers & 6 \\
\hline Thickness $[\mathrm{mm}]$ & 6 \\
\hline
\end{tabular}

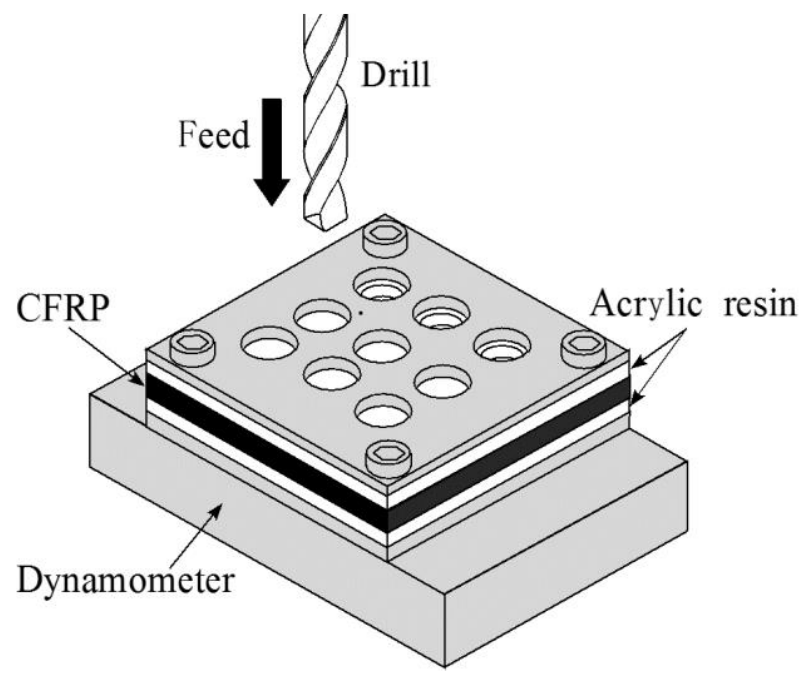

Fig. 2. Experimental method

Table 2. Cutting conditions

\begin{tabular}{|c|c|}
\hline Workpiece material & CFRP Acrylic resin \\
\hline Tool material & SKH57 \\
\hline Diameter of drill & $6 \mathrm{~mm}$ \\
\hline Point angle $\left[{ }^{\circ}\right]$ & 118 \\
\hline Helix angle $\left[^{\circ}\right]$ & 32 \\
\hline Clearance angle $\left[{ }^{\circ}\right]$ & 16 \\
\hline Cutting speeds $V[\mathrm{~m} / \mathrm{min}]$ & $18.5,25.1,33.9$ \\
\hline Feed rate $f[\mathrm{~mm} / \mathrm{rev}]$ & $0.1,0.2,0.3$ \\
\hline
\end{tabular}


Figure 3 shows the drilling methods. In the following of this paper, the only CFRP plate was described as "CFRP", the workpiece in which the acrylic resin plate was stacked on the lower side of the CFRP plate was described as "CFRP+Acylic", and the workpiece in which the acrylic resin plate was stacked on both the upper and lower sides of the CFRP plate was described as "Acylic+CFRP+Acylic".

Measurement of thrust force $F_{z}$ was performed using a Kistler 9129AA, 3 axis dynamometer. The dynamometer is a piezoelectric quartz force transducer affixed to a table of machining centre. After drilling tests, the cutting state of the hole was observed with a digital microscope.

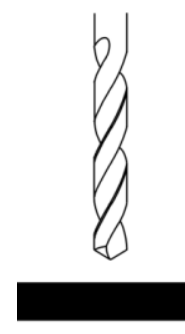

(a)

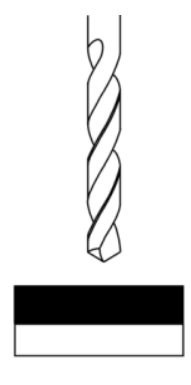

(b)

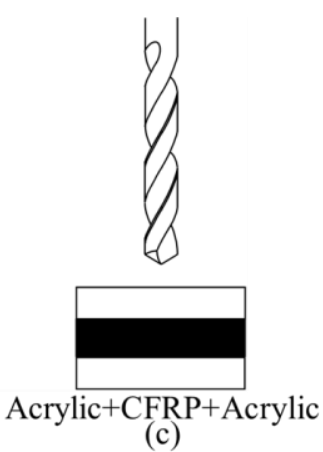

(c)

Fig. 3. Drilling method

\subsection{EXPERIMENTAL RESULTS}

Figure 4 shows the microphotographs after drilling 10 holes. In the drilling of "CFRP", burrs and delamination were observed at both the entry and exit sides of the holes. In the drilling of "CFRP+Acrylic", suppression of burr was observed on the exit side of the holes. In the drilling of "Acrylic+CFRP+Acrylic", suppression of burrs and delamination was observed on both the entry and exit sides of the holes. These tendencies were observed at all cutting speeds and feed rates.

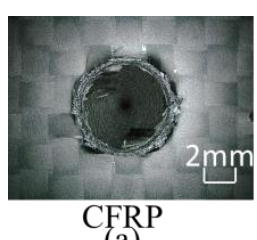

CFRP

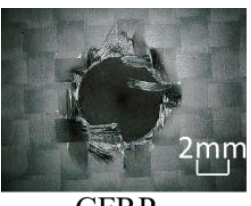

CFRP

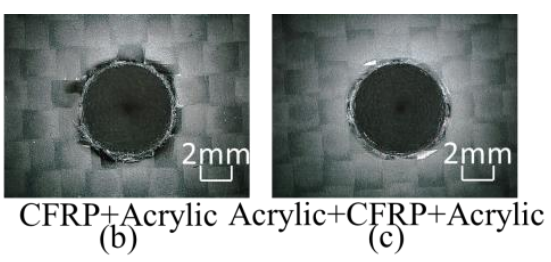

(i) Entry side

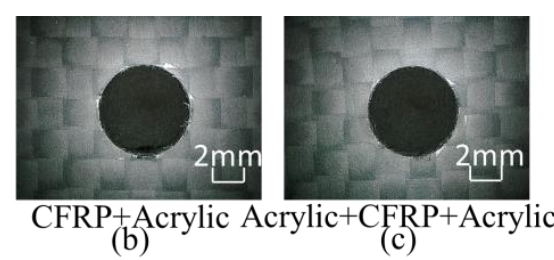

(ii) Exit side

Fig. 4. Microphotograph of drilled holes ( $V=18.5 \mathrm{~m} / \mathrm{min}, f=0.2 \mathrm{~mm} / \mathrm{rev}, 10$ holes $)$ 
Figure 5 shows the thrust force when the $10^{\text {th }}$ hole was drilled. The maximum value of thrust force is almost the same in the drilling of "CFRP" and "CFRP+Acrylic". On the other hand, the maximum value of thrust force in the drilling of "Acrylic+CFRP+Acrylic" is smaller than that in the other drilling methods. In the drilling of "Acrylic+CFRP+Acrylic", it is thought that chatter at the start of CFRP drilling was suppressed and thrust force was decreased because the tool stabilized during the first acrylic drilling.

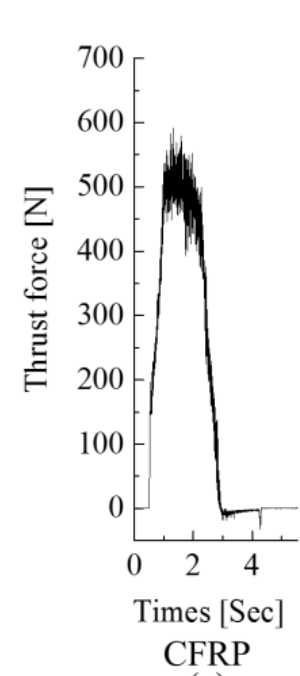

(a)

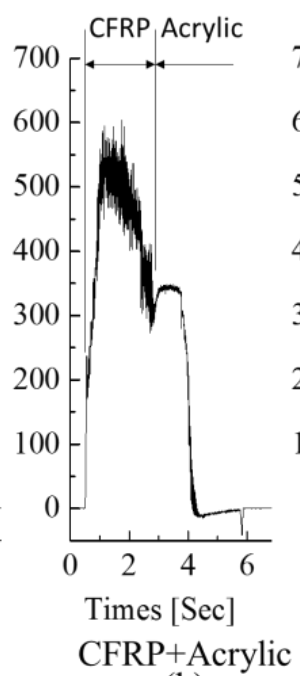

(b)

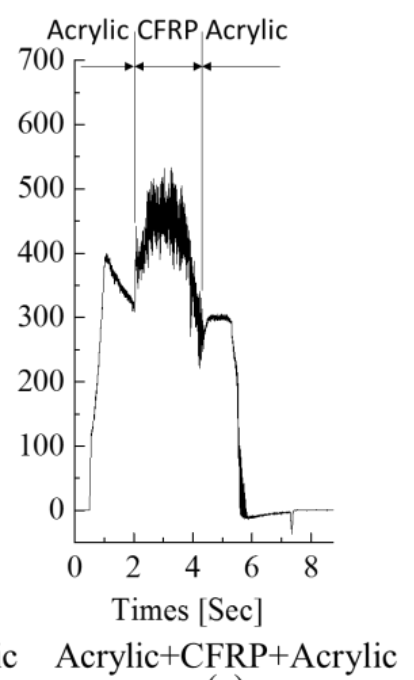

(c)

Fig. 5. Thrust force ( $V=18.5 \mathrm{~m} / \mathrm{min}, f=0.2 \mathrm{~mm} / \mathrm{rev}, 10^{\text {th }}$ hole $)$

Figure 6 shows the relationship between the maximum value of thrust force and the number of holes. Maximum value of thrust force increases linearly with increasing the number of holes. Furthermore, the maximum value of thrust force in the drilling of "Acrylic+CFRP+Acrylic" is smaller than that in the drilling of the other methods with increasing the number of holes.

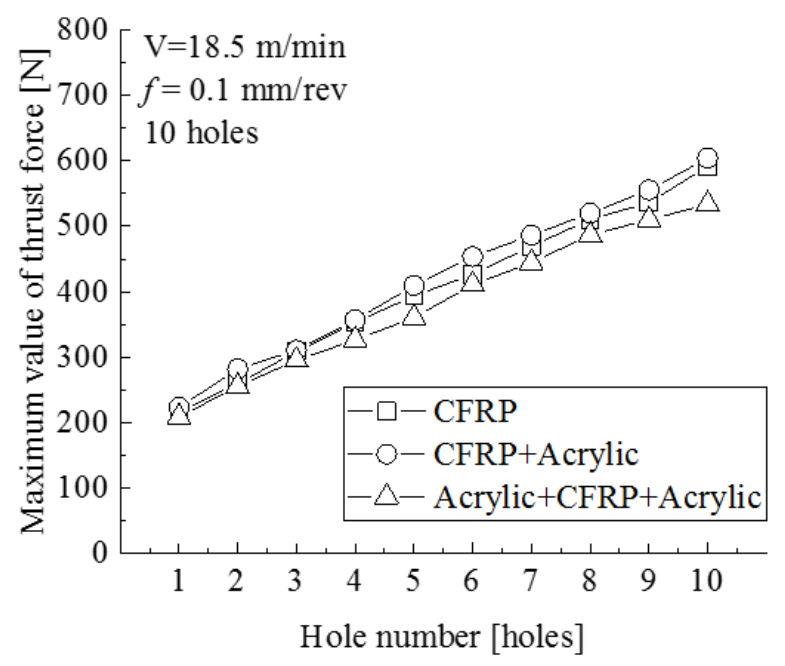

Fig. 6. Effects of hole number on maximum value of thrust force $(V=18.5 \mathrm{~m} / \mathrm{min}, f=0.2 \mathrm{~mm} / \mathrm{rev})$ 
Figure 7 shows the relationship between the maximum value of thrust force and the feed rate. There is no difference in maximum value of thrust force due to three drilling methods. Furthermore, they have not changed by the feed rate in three drilling methods. In general, the thrust force is expected to increase with increasing the feed rate. However, it is considered that the thrust force increases at low feed rates because the time while the tool is in contact with the fibers increases with decreasing the feed rate.

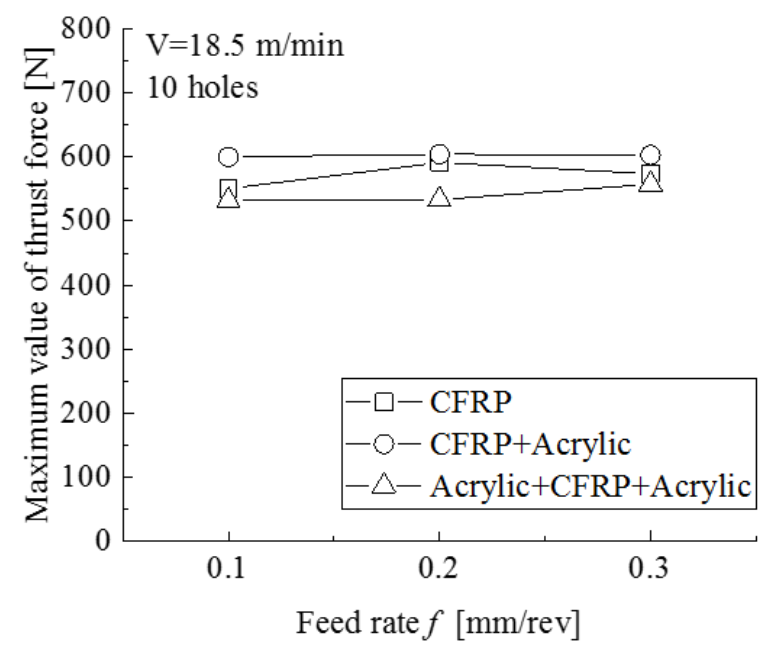

Fig. 7. Effects of feed rate on maximum value of thrust force ( $V=18.5 \mathrm{~m} / \mathrm{min}, 10$ holes $)$

Figure 8 shows the relationship between the maximum value of thrust force and the cutting speed. There is no difference in maximum value of thrust force due to three drilling methods. However, they increase gradually with increasing the cutting speed in three drilling methods. It is thought that the thrust force increased because the tool wear increased due to the temperature increase with the increase of the cutting speed.

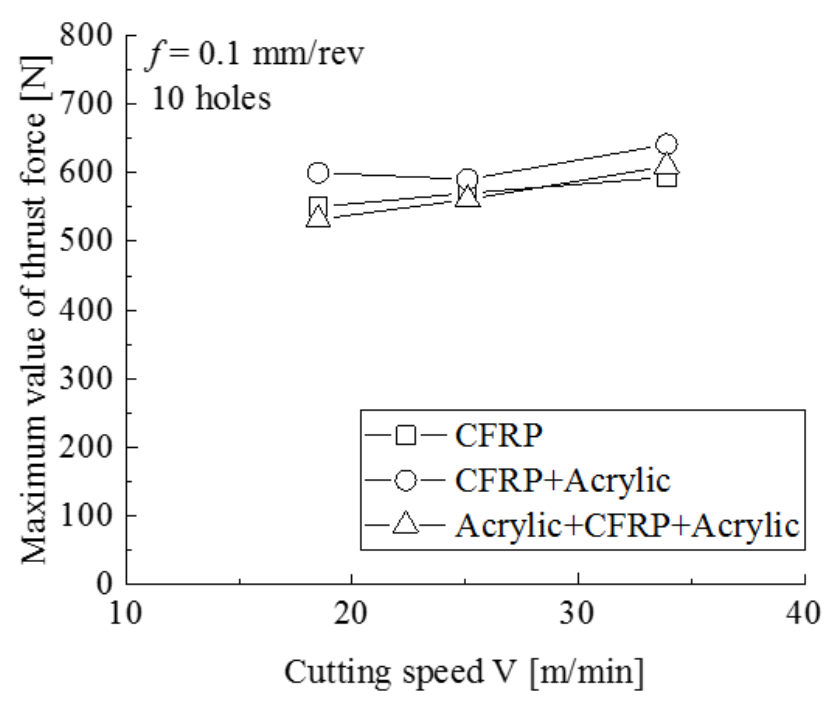

Fig. 8. Effects of cutting speed on maximum value of thrust force $(f=0.2 \mathrm{~mm} / \mathrm{rev}, 10$ holes $)$ 


\section{INTERNAL SURFACE OF HOLE}

\subsection{EXPERIMENTAL PROCEDURE}

In order to investigate the effect of stacking acrylic resin plate on CFRP in more detail, the following drilling test was conducted. A pre-cut workpiece was used in the experiment to more accurately examine the condition of the inner surface of the hole, as shown in Fig. 9. The drilling tests were performed using a vertical machining centre. The cutting conditions are the same as in Table 2. The surface roughness of the inner surface of the drilled hole were measured with a contact-type roughness measuring machine.

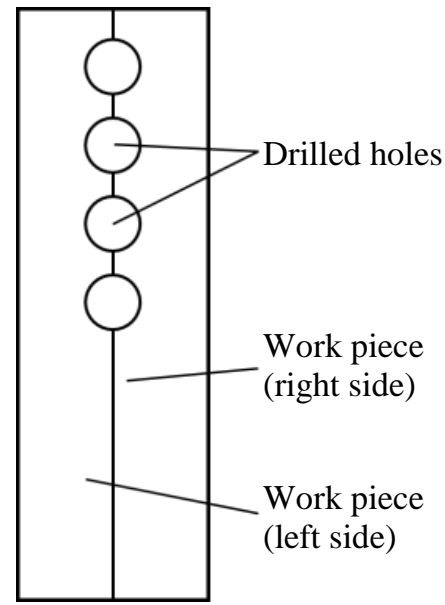

Fig. 9. Pre-cut workpiece

\subsection{EXPERIMENTAL RESULTS}

Figure 10 shows the relationship between the maximum height roughness $R_{y}$ and the feed rate. $R_{y}$ in the drilling of "Acrylic+CFRP+Acrylic" is smaller than that in the drilling of "CFRP+Acrylic" at feed rates of $0.2 \mathrm{~mm} / \mathrm{rev}$ or more. Consequently, it is considered that stacking acrylic resin plate on the upper side of CFRP leads to improved machining accuracy on the inner surface of the hole under conditions where the feed rate is relatively high. However, this tendency must be investigated under a wide range of conditions.

Figure 11 shows the relationship between the maximum height roughness $R_{y}$ and the cutting speed. $R_{y}$ in the drilling of "Acrylic+CFRP+Acrylic" is slightly smaller than that in the drilling of "CFRP+Acrylic" at cutting speeds of $25.1 \mathrm{~m} / \mathrm{min}$ or more. Consequently, it is considered that stacking acrylic resin plate on the upper side of CFRP leads to improved machining accuracy on the inner surface of the hole under conditions where the cutting speed is relatively high. However, this tendency must be investigated under a wide range of conditions.

As a result, it was found that stacking acrylic resin on the upper side of CFRP can be expected to improve the machining accuracy of the inner surface of the drilled hole. 


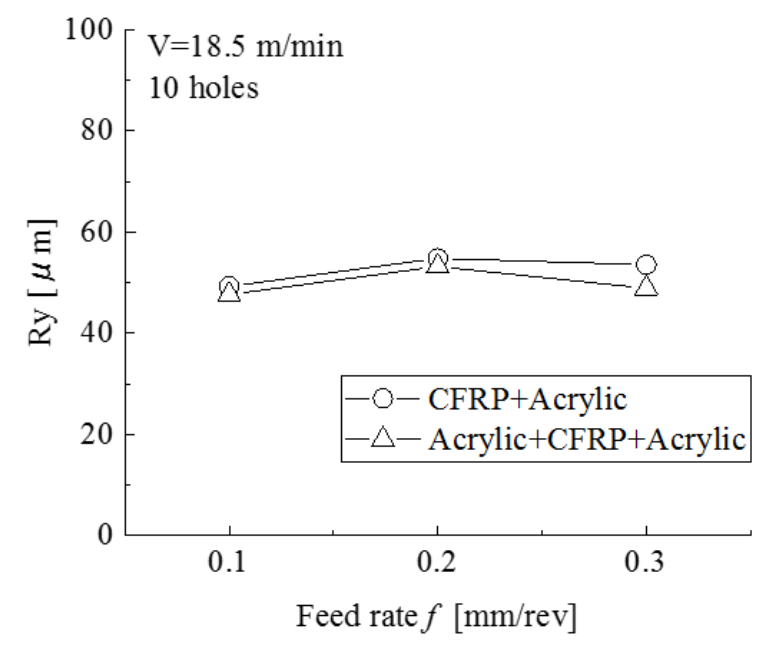

Fig. 10. Effects of feed rate on maximum height roughness $R_{y}(V=18.5 \mathrm{~m} / \mathrm{min}, 10$ holes $)$

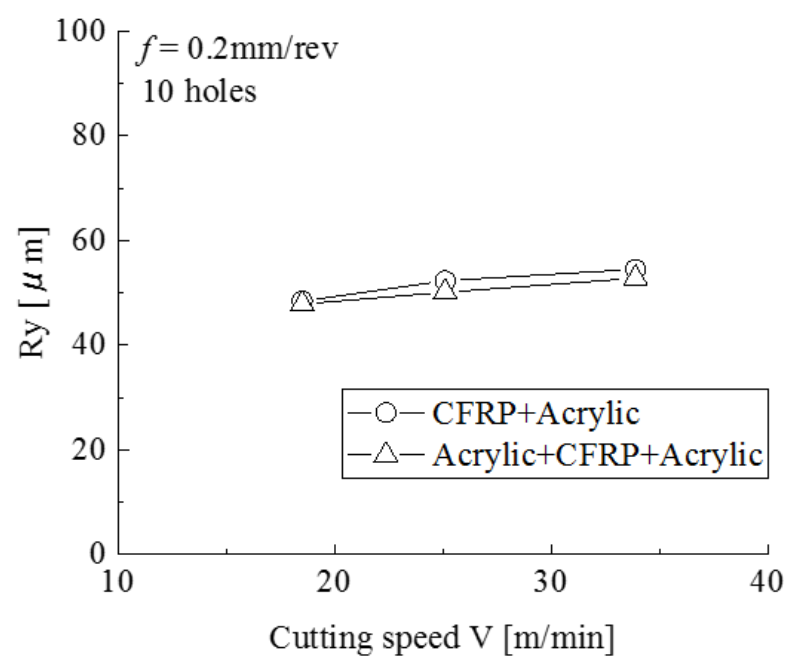

Fig. 11. Effects of cutting speed on maximum height roughness $R_{y}(f=0.2 \mathrm{~mm} / \mathrm{rev}, 10$ holes $)$

\section{CONCLUSIONS}

In drilling, the effect of "simultaneous cutting" by stacking acrylic resin on CFRP was investigated. Results obtained by drilling tests were as follows.

1. Stacking acrylic resin on CFRP leads to suppression of burrs and delamination in CFRP drilled holes and reduction of thrust force. However, the relationship between these results and cutting conditions could not be clarified.

2. Stacking acrylic resin on both the upper and lower sides of the CFRP plate can be expected to improve the machining accuracy of the inner surface of the drilled hole.

3. The machined surface with the highest quality was obtained from the workpiece in which acrylic resin was stacked on both the upper and lower sides of the CFRP plate. 


\section{REFERENCES}

[1] STEININGER A., BLEICHER F., 2018, In-process monitoring and analysis of dynamic disturbances in boring and trepanning association (BTA) deep drilling, Journal of Machine Engineering, 18/4, 47-59.

[2] HEISEL U., SABOU F., MAIER D., 2012, Relation of process and condition monitoring at deep hole drilling, Journal of Machine Engineering, 12/1, 99-110.

[3] PALANIKUMAR K., SRINVASAN T., RAJAGOPAL K., LATHA B., 2014, Thrust force analysis in drilling glass fiber reinforced/polypropylene (GFR/PP) composites, Materials and Manufacturing Processes, 31/5, 581-586.

[4] WAKABAYASHI H., KOIKE R., KAKINUMA Y., AOYAMA T., SHIMADA H., HAMADA S., 2016, Ultrasonic-vibration-assisted micromachining of sapphire, Materials Science Forum, 247-252.

[5] PECAT O., RENTSCH R. and BRINKSMEIER E., 2012, Influence of milling process parameters on the surface integrity of CFRP, Procedia CIRP, 466-470.

[6] SASAHARA H., KIKUMA T., KOYASU R., YAO Y., 2014, Surface grinding of carbon fiber reinforced plastic (CFRP) with an internal coolant supplied through grinding wheel, Precision Engineering, 38, 775-782.

[7] TETI R., 2002, Machining of composite materials, CIRP Annals Manufacturing Technology, 51, 611-634.

[8] DEVIM J.P., REIS P., 2005, Damage and dimensional precision on milling carbon-fiber-reinforced plastics using design experiments, Journal of Materials Processing Technology, 160/2, 160-167.

[9] BILEK O., RUSNAKOVA S., ZALUDEK M., 2016, Cutting-tool performance in the end milling of carbon-fiberreinforced plastics, Materials and Technology, 50/5, 819-822.

[10] TANAKA H., YOSHITA T., 2015, Machinability evaluation of inclined planetary motion milling system for difficult-to-cut materials, Key Engineering Materials, 656-657, 320-327.

[11] SAKAMOTO S., IWASA H., 2012, Effect of cutting revolution speed on cutting temperature in helical milling of CFRP composite laminates, Key Engineering Materials, 523-524, 58-63.

[12] OZDEN I., ELAHEH G., 2013, Comparative study of tool life and hole quality in drilling of CFRP/titanium stack using coated carbide drill, Machining Science and Technology, 17, 380-409.

[13] SENTHILKUMAR M., PRABUKARTHI A., KRISHNARAJ V., 2013, Study on tool wear and chip formation during drilling carbon fiber reinforced polymer (CFRP)/titanium alloy (Ti6Al4V) stacks, Procedia Engineering, 64, 582-592. 